funds should not only be increased in volume but that arrangements should be made for sufficient monies from them to be available for several decades ahead. This is particularly important so far as assistance to Colonial education is concerned. Our review of the evidence which we have heard leads us to the conclusion that progress towards the better application of science and technology in Colonial territories depends primarily on opportunities for elementary education being widely extended. Until education is so broadly based that the vast majority of the indigenous population has become literate there will be no chance of obtaining technically trained field workers in sufficient numbers; nor will such field workers as do exist be able to obtain from villagers and peasantry that degree of intelligent co-operation without which theory, however sound, can never be translated into practice.

"It appears unquestionable that the successful development of the Colonial Empire depends chiefly on the more efficient application of modern scientific knowledge and methods in such fields as agriculture, forestry, medicine or veterinary science and in other activities connected with the development of natural resources. But such efficient application depends in its turn very largely upon the technical competence of the indigenous populations and their ability to take an active part in the process."

\section{BUDGETS OF THE SCIENTIFIC DEPARTMENTS OF THE UNIVERSITY OF CAMBRIDGE}

\section{By SIR LAWRENCE BRAGG, O.B.E., F.R.S.}

A $\mathrm{N}$ analysis has recently been made of the recurdepartments in the University of Cambridge. A brief summary of the figures is given below, as they may be of general interest. I am much indebted to the University treasurer, Dr. H. M. Taylor, for providing me with the material and assisting me in preparing this summary. The figures relate to the financial year $1950-51$.

Some explanation of the basis of the analysis is necessary. For some years an analysis has been made of the expenditure in the Cavendish Laboratory, and a reasonable allocation of the budget between research and teaching shows that one research worker costs as much as ten full-time undergraduates. In arriving at this figure it is reckoned that the time of the staff is divided equally between teaching and research, and other items, such as assistants' wages, materials and apparatus, are allowed for. The 'cost per effective research worker' is arrived at by adding to tho number of staff, holders of research fellowships and scholarships and Ph.D. students, one-tenth the number of full-time undergraduates (due allowance being made when undergraduates only get a part of their teaching in the Laboratory), and dividing the total itemized costs by the total number so obtained. In the Cavendish Laboratory, for example, an estimated cost of $£ 755$ per 'effective research worker' implies a cost of $£ 75$ a year for an undergraduate student. It must be remembered that the last figure only represents the University's contribution to his teaching, a very substantial part of which is provided by his College.
The expenditure includes the contributions to research made by outside bodies such as the Department of Scientific and Industrial Research and other government bodies, and by industry ; in other words, the complete budget of each department. The capital cost of buildings and of large items of equipment such as the cyclotron is not included ; but the recurrent expenditure of maintenance and of providing assistants to run apparatus has been taken into account. A proportionate share of the cost of the central administration and of the services of the Buildings Syndicate is added to the budget of each department.

For the scientific departments as a whole the staff and students are made up of : graduate staff, 340 ; research students, 561; undergraduates, 2,870; research assistants, 80; and assistant staff, 745 . The volume of the buildings is $\mathbf{1 2 . 7 9 7}$ million cu. ft., the volume per 'effective research worker' being $15,000 \mathrm{cu}$. ft. The current expenditure during the financial year 1950-51 for the scientific departments is as follows:

\begin{tabular}{|l|r|c|} 
& Totals & $\begin{array}{c}\text { Per effective } \\
\text { research } \\
\text { worker }\end{array}$ \\
\hline Administration & & $£ 69$ \\
Teaching and research salaries & 41,246 & 346 \\
Assistant staff wages & 156,095 & 131 \\
Supplies & 149,386 & 125 \\
Heat, light, water* & 32,185 & 27 \\
Repairs and maintenance* & 49,673 & 42 \\
\hline Totals & $£ 880,849$ & $£ 7 \pm 0$ \\
\hline
\end{tabular}

* The annual cost of heat, light and water per thousand cubic feet is $£ 2 \cdot 5$, and that of repairs and maintenance $£ 3 \cdot 9$.

When a research student is admitted to one of the Cambridge laboratories, he is therefore in effect being given a research grant of $£ 740$ a year. This does not, of course, imply that, if an extra research worker is taken on, the budget is automatically increased by this amount, or vice versa if the number drops, since many of the charges are fixed charges which can only be altered by a general expansion or contraction of the department taking place over a long period. The figures do not include the fellowships, scholarships or maintenance allowances paid to research workers who are not on the staff. If we take these grants to be on the average $£ 500$ a year, the cost to the community of maintaining a scientific research worker at Cambridge is, in round figures, $£ 1,250$ a year.

The figures for individual departments vary considerably, but most lie in the range $£ 600-900$ a year. The costs of physics and chemistry, which are the largest scientific departments, are very close to the average value. For the Cavendish Laboratory the staff and students are made up of : graduate staff, 32 ; research students, 117 ; undergraduates, 544 ; and assistant staff, 88 (including research assistants). The expenditure for the Cavendish Laboratory is as follows :

\begin{tabular}{|c|c|c|}
\hline & Total cost & $\begin{array}{l}\text { Cost per } \\
\text { research } \\
\text { worker }\end{array}$ \\
\hline 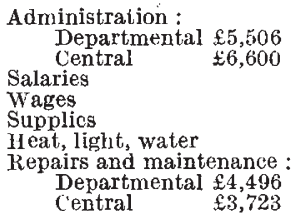 & $\begin{array}{r}£ 12,106 \\
44,752 \\
25,694 \\
33,419 \\
7,277 \\
\\
8,219\end{array}$ & $\begin{array}{r}£ 70 \\
257 \\
148 \\
192 \\
41\end{array}$ \\
\hline Totals & $£ 131,467$ & $£ 755$ \\
\hline
\end{tabular}


As might be expected, costs for the literary faculties are considerably lower. When calculated on the same basis of one research worker being equivalent to ten undergraduates, the average figure is $£ 416$ a year as compared with $£ 740$ a year in the scientific faculties. Assistants' wages, supplies and services are expensive items in the scientific budgets.

\section{DEPOPULATION AND RURAL LIFE IN SCOTLAND}

$\mathrm{I}^{\mathrm{N}}$

1948, the Social Survey of the Central Office of Information was asked by the Department of Health for Scotland to carry out, in selected areas of Scotland, an investigation into rural living conditions and the causes of rural depopulation. The three areas were the Solway counties of south-west Scotland, the Tweed Basin, and north-east Scotland, within the counties of Aberdeen and Banff.

The Solway area was the subject of a detailed report. In the other two areas the results of the investigations showed that conditions there differed only slightly from those obtaining in the south-west. A cursory examination of the three sets of results revealed that, in the districts that were surveyed, the main problems of rural life remained the same, although sometimes presented with slightly different emphases. It seems possible, therefore, that the same kind of remedial measures would be applicable to all the survey areas. On the other hand, the analyses of the results from the Solway survey left in doubt the fundamental factors that had caused the decline of the population of the area. An attempt has therefore been made to isolate these factors with the aid of material from the Tweed and the Aberdeen inquiries, together with the results of a postal questionnaire sent to persons known to have migrated in the preceding twenty years*.

A summary of the major findings showed that, in the rural areas studied, a tenth of the adult population said they would prefer to move away; but the proportion varied from county to county. Wigtownshire and Peebleshire showed a racber higher proportion of potential migrants (those counties being more isolated and less well served with modern amenities than others), while in the better-served counties of Selkirk and Berwick the proportion was somewhat lower than the average. Only a small minority (17 per cent) of the potential migrants had actually made plans to move within a year of the date of interview, giving an average of $\mathbf{1} \cdot 7$ per cent of the adult population of the survey areas whose desire to move had reached the stage of action. People related to earlier migrants tended to become potential migrants themselves slightly more often than people who were not so related. They were also rather more conscious of the advantage of urban forms of life.

Analysis showed that national and local government, the building industry and the personal service industries produced a rather higher than average proportion of potential migrants. In contrast, there was a significantly smaller proportion of potential * Depopulation and Rural Life in the Solway Counties. By Bertram
Hutchinson. (N.S. 120.) Pp. iv $+110+25$ plates. Depopulation and Rural Life in the Tweed Valley. By Bertram Hutchinson. (N.S. 120b.) Pp. fi +60 . Depopulation and Rural Life in Aberdeen. By Bertram Hutchinson. (N.S. 120c.) Pp. 63. Depopulation and Rural
Life in Scotland. (N.S. 120d.) Pp. $11+36$. (London : Soclal Survey, 1949.) migrants from among those employed in agriculture, and from people who were retired or had no occupation. On the other hand, the desire to migrate was most frequently found among professional workers, clerical workers and the managerial and executive grades. The supervisory and skilled operative grades produced a smaller than average proportion of potential migrants. Within agriculture, farmers, bailiffs and foremen showed the smallest proportion of potential migrants of all occupations.

The desire to move was expressed rather more often by the young and the single people than by the old and the married. Thus, while of the general population of the survey areas 20 per cent were under thirty years of age, among the potentially migrant group 37 per cent were of this age.

The situation of the informant's dwelling had only a small degree of association with his desire to move or to remain. Thus, people living in an isolated house, or in a house situated in a small lonely group, were less likely to wish to move away than people living in the burghs. Similarly, people whose houses had no road access were less likely to wish to move than people living on main and other metalled roads. There was a greater degree of association, however, between the informant's subjective estimate of the convenience of the location of his home and the desire to move. Nearly three times as many people who said their homes were situated inconveniently as of those who thought them conveniently located said they wished to move to a town. The majority of houses thought 'inconveniently' placed, however, were in burghs or villages. An analysis of some of the actual conditions of housing and amenity in the survey areas showed that the households of potential migrants were, slightly more often than the average, enjoying a main water supply and main drainage, and were more often provided with gas, electricity, telephone and refuse collection services.

Visits to burghs were rather more frequent among potential migrants than among other people. The reasons for their visits laid a rather greater emphasis upon social calls and entertainments than upon business and marketing, compared with the rest of the rural population.

The reasons which potential migrants gave for their preference appeared to fall into the following major categories : the desire for a better job; the desire to escape rural loneliness and stagnation; the wish for change and new experience; and miscellaneous answers of which a considerable proportion referred to factors such as marriage, transfer by employer, and personal family reasons. Replies to a postal questionnaire showed that migrants had made a considerable advance in occupational skill and position after leaving rural areas. As many as 50 per' cent of past migrants said they would not have moved away from the countryside had a better choice of jobs been available there.

From these findings it is difficult to point without hesitation to any single factor which has led to the process of depopulation. The explanations given by past and potential migrants for their wish to migrate offer the most solid indications as to the causes of rural depopulation. Both in the past and to-day the desire for occupational advance appears to have been the most frequent cause of migration, while evidence suggests that migration has, in fact, been accompanied by a rise in occupational status. Secondly, there was a desire to escape from the stagnation and solitude of rural life, a desire for new experience and the more 